\title{
Aplicación de la crítica de los dispositivos a la cena performativa "El Somni" de El Celler de Can Roca y Fran Aleu
}

\begin{abstract}
Application of the critique of dispositives to the performative dinner "El Somni" by El Celler de Can Roca and Fran Aleu
\end{abstract}

\begin{abstract}
Anne-Claire Yemsi-Paillissé [CV]
ORCID] [ $\mathrm{G}$ Google Scholar].

Profesora del Instituto Superior de Turismo, Hostelería y Alimentación (ISTHIA), Laboratorio LLACREATIS - Universidad de Toulouse. Francia

anne-claire.paillisse@univ-tlse2.fr
\end{abstract}

Yanet Acosta Meneses [CV] ORCID] [ $\mathrm{E}$ Google Scholar].

Profesora del Departamento de Ciencias de la Comunicación y Sociología

Universidad Rey Juan Carlos (URJC), Madrid. España

myanet.acosta@urjc.es

Monique Martinez [CV] ORCID] [ $\mathrm{E}$ Google Scholar].

Profesora Catedrática del Departamento de Lengua, Literatura, Civilización española - Laboratorio LLA-CREATIS - Universidad de Toulouse. Francia

monique.martinez@univ-tlse2.fr

Elvira Calvo Gutiérrez [CV]

ORCID] [ 6 Google Scholar].

Profesora del Departamento de Periodismo y Nuevos Medios

Universidad Complutense de Madrid (UCM). España

ecalvogu@ucm.es

\section{Abstracts}

[ES] A partir de los conceptos acunados por la Crítica de los dispositivos se disciernen y analizan los niveles técnicos, pragmáticos y simbólicos (a menudo imbricados) de la ópera gastronómica "El Somni” (The Dream) propuesta en 2013 por los hermanos Roca y Fran Aleu. Gracias a este estudio, 
observamos que "El Somni” resulta ser una transgresión de la concepción tradicional de la gastronomía como herramienta para la obtención de placer o de felicidad a través del gusto y

un dispositivo subversivo que sacude las estructuras estándar y las expectativas puestas en una comida, con lo que la cocina de vanguardia trasciende lo meramente alimentario para convertirse en un lenguaje artístico. Y pese a ello, el comensal mantiene sus hábitos de socialización.

[EN] From the concepts cradled by the critique of dispositives are discerned and analyzed the technical, pragmatic and symbolic (often overlapping) levels of the gastronomic opera "El Somni" (The Dream) proposed in 2013 by the brothers Roca and Fran Aleu. Thanks to this study, we observed that "El Somni" turns out to be a transgression of the traditional conception of gastronomy as a tool for obtaining pleasure or happiness through taste and a subversive dispositive that shakes the standard structures and the expectations placed on a meal, with which avant-garde cuisine transcends the merely alimentary to become an artistic language. And despite this, the diner keeps its socialization habits.

\section{Keyword}

[ES] Gastronomía; dispositivos; arte; cocina de vanguardia.

[EN] Gastronomy; dispositives; art; molecular cuisine.

\section{Contents}

[ES] 1. Introducción 2. Contextualización 2.1. El arte culinario en la historia 2.2. La cena gastronómica como espectáculo: actuaciones en la alta cocina española 2.3. Más allá del espectáculo: las relaciones entre "El Somni", el teatro y la performance 3. Metodología 4. Análisis y resultados 4.1. El nivel técnico (I) 4.2. El nivel pragmático (II) 4.3. El papel de las pantallas 4.4. La dimensión simbólica/axiológica: un menú transgresor 5. Discusión y conclusiones 6 . Referencias bibliográficas [EN] 1. Introduction 2. Contextualization 2.1. The culinary art in history 2.2. The gastronomic dinner as a show: performances in Spanish haute cuisine 2.3. Beyond the show: the relationships between "El Somni", theater and performance 3. Methodology 4. Analysis and results 4.1. The technical level (I) 4.2. The pragmatic level (II) 4.3. The role of screens 4.4. The symbolic / axiological dimension: a transgressive menu 5. Discussion and conclusions 6. List of references

Traducción de artículo por Yuhanny Henares (Traductora académica, Universitat de Barcelona)

\section{Introducción}

Esta investigación forma parte de un proyecto franco-español que se propone estudiar las obras la alta cocina española actual desde una perspectiva innovadora y transdisciplinaria. Nuestro objetivo es construir una red de colaboración entre dos campos de investigación, que por lo general están separados: los estudios alimentarios (las ciencias sociales aplicadas a la esfera alimentaria) y los estudios artísticos y lingüísticos (las ciencias humanas con una perspectiva intercultural). Los investigadores involucrados en el proyecto son españoles y franceses y este proyecto ha contado con una financiación del ISTHIA (Instituto superior de turismo, hotelería y alimentación) y del laboratorio CERTOP (Centro de estudios y de investigación sobre el trabajo, las organizaciones y el poder) de la Universidad de Toulouse - Jean Jaurès. 
Este trabajo tiene como objetivo aplicar por primera vez la crítica de los dispositivos (desarrollada en el laboratorio LL@-Creatis de Toulouse desde 2000) a un proyecto experimental gastronómico realizado en España “El Somni” (“El Sueño”).

“El Somni” está dirigido por el artista Franc Aleu y los tres cocineros Joan, Josep y Jordi Roca de “El Celler de Can Roca” (3 estrellas en la guía Michelin, y Mejor Restaurante del Mundo 2013 y 2015 en la revista Restaurant) ubicado en Girona, España. Este proyecto se inscribe en la dinámica creativa de los hermanos Roca: se trata de experimentar - la noción de experimentación es fundamental en el quehacer gastronómico de los tres restauradores- a raíz de una metodología de creación innovadora. Lo inmersivo y lo pluridisciplinar pueden permitir renovar la experiencia gastronómica y más prosaicamente, pueden llevar a concebir unos platos inéditos para nutrir la carta del restaurante. La sed de búsqueda y la mente investigadora que anima a los tres hermanos Roca, su voluntad de trabajar en colaboración con otros oficios y disciplinas y su concepción de la cocina como un área de creatividad estrechamente vinculada con la esfera artística, les hace, en parte, los herederos de la figura tutelar de Ferran Adrià (por cierto, Josep Roca pasó por los fogones del célebre restaurante "El Bulli” de Cala Monjoi).

“El Somni” es un experimento multidisciplinar, cuyo mayor fruto es "Una ópera en doce platos, un banquete en doce actos”. Esta “cena” peculiar se realizó en Barcelona el 6 de mayo de 2013 y en ella participaron 12 comensales que degustaron 12 platos con 12 vinos en 12 actos (los mismos que tiene una ópera). El experimento dio origen a la grabación de un documental, a la edición de un libro álbum y a una exposición en el Centro de Arte Santa Mónica de Barcelona.

Al parecer, todos los medios y géneros narrativos de "El Somni" —videoarte, música filarmónica y canto, artes culinarias (design, sumillería, cocina) - convergen para contar una historia con la sucesión cronológica de un momento inicial o expositivo (el lento hundimiento de Astrid en el sueño), de varias aventuras u obstáculos (la metamorfosis de Astrid en una sirena, su historia de amor con Adonis, y la muerte del amado) y finalmente de un desenlace (la gloria y el despertar del sueño, del somni). El menú gastronómico que los hermanos Roca imaginaron no sólo sigue esta trama narrativa, sino que también respeta la estructura reconocible de un menú de degustación gastronómica, con comida y acompañamiento de vinos.

El objetivo es llevar a los 12 comensales a puntos álgidos de emoción, de sorpresa y también de temor, gracias al uso de medios diversos y complementarios como la ópera, la poesía, las artes escénicas, el canto, la filosofía, la pintura, el cine, la música y la cocina. En la mente de los creadores, la cocina debe de seguir siendo el elemento central y estructural en el proyecto. Se trata, ante todo, según el propio Joan Roca de descontextualizar para "experimentar la cocina más allá del restaurante”. De alguna manera, "el Somni” ahonda en la capacidad de la cocina para comunicar sobre lo más ontológico, lo más trascendental de la vida y la sensorialidad humanas, es decir que los creadores se proponen ilustrar con sabores, olores y texturas, momentos intangibles de la experiencia humana, desde el nacimiento hasta la muerte de los protagonistas de la ópera.

La cena propuesta en "El Somni” es pues una experiencia multisensorial, una muestra de obra gastronómica total, es decir una producción artística que es a la vez gustativa, visual, auditiva, olfativa, táctil e intelectual. 


\section{Contextualización}

\subsection{El arte culinario en la historia}

La relación entre las artes y la esfera culinaria es un objeto de estudio bastante complejo, primero porque el propio concepto de «arte» es eminentemente problemático y dinámico. El filósofo Jacques Rancière insiste en la importancia hoy en día de la dimensión estética (del griego "aethesis"). A su modo de ver, "para que haya arte, tiene que haber una mirada que lo identifique como tal" (Rancière, 2004, 27). De modo que lo artístico no se definiría exclusivamente según unas categorías plásticas estancadas (las Bellas Artes) y como el ejercicio bien arreglado de un saber hacer (la "poeisis" griega), sino que, sobre todo desde el siglo XIX-XX, se van considerando como obras de arte varias formas de creación que tienen como punto en común el proponer, más allá de "maneras de hacer”, auténticas "maneras de ser sensibles" (Rancière, 2004:25): el cine, la fotografía, el tebeo, etc. De modo que en esta época la lista de las artes reconocidas como tal se alarga hasta llegar a nueve o diez categorías tienen el mérito de ensanchar la mirada sobre unas formas de auténtica creación artística, desconsideradas hasta aquel entonces.

Sin embargo, la expresión "arte culinario", cuando se utiliza especialmente para señalar la actividad propia del cocinero, es muy reciente e incluso sigue siendo puesta en duda hoy en día. Este fenómeno es debido en gran parte al menosprecio que la cocina ha sufrido en la cultura occidental, sobre todo por ser una práctica "utilitaria", por estar "vinculada con los sentidos bajos, con la animalidad" (Flandrin, 1992: 155).

De hecho, la expresión "arte culinario" fue utilizada primero para designar unas formas de creación todavía dependientes de las categorías artísticas clásicas como pintura, teatro o música y enraizadas en unas formas plásticas identificadas, que utilizaban la comida bien como tema, bien como material capaz de transmitir un mensaje artístico. El bodegón, género que sin duda alcanza su máxima expresión por parte de los pintores flamencos y españoles del siglo XVII y XVIII y que sigue siendo un género al que recurren los artistas contemporáneos, podría ser considerado como una de las primeras muestras pictóricas del arte culinario de los primeros tiempos (Hartung, 2002: 15-22).

De modo que la conversión de la cocina en arte comenzó fuera de su propio campo en el "eat art” con las actuaciones de Daniel Spoerri en los años 1960 con su "restaurante-galería”, o Antoni Miralda, Dorothée Selz, Gina Paine o Sophie Calle, el postmoderno "gastrodrama” (Saumell i Olivella, 2011) como Nutritivo de Sergi Faustino, o Accidens. Matar para comer de Rodrigo García, las novelas gastronómicas (las novelas protagonizadas por Pepe Carvalho de Manuel Vázquez Montalbán o las de Andrea Camilleri o las más recientes novelas de Xabi Gutiérrez o de Yanet Acosta), están utilizando la comida como un material o un motivo importante de su creación.

Paralelamente a la generación de las obras anteriormente citadas, la concepción del «arte culinario» occidental, no sólo como material para otros géneros artísticos sino como un género independiente, es el resultado de un largo proceso que comenzó con la codificación de las prácticas de mesa en el renacimiento, cuando las casas nobles empezaron a poner los cuerpos a distancia de la comida con la adopción de los cubiertos individuales y más tarde con la generalización del uso tenedor se ilustra esta evolución (Neirink y Poulain, 2007: 53). El proceso continuó con la intelectualización de la cocina en la segunda mitad del siglo XVII, con la aparición de unos escritos que dejan percibir, según la historiadora Béatrice Fink, "los fundamentos de una cocina susceptible de ser estetizada en 'armonía de los sabores"” (Fink, 1995: 19) y el surgimiento de un "campo de recepción” para la cocina (Champion, 2010: 23). Poco a poco, con la popularización del restaurante como estandarte de la 
sociedad burguesa y urbana post revolucionaria en Francia (en París hay unos cien restaurantes en 1789 y se cuentan más de tres mil en 1815), la imagen del cocinero evolucionó hacia una figura de mayor autonomía y autoridad, como lo que escribe Caroline Champion cuando hace un interesante paralelismo entre el modelo de ascenso social y la salida del anonimato de los artistas, de la Edad Media al Renacimiento, y el ascenso de los grandes cocineros en el siglo XX (Champion, 2010: 7080).

Posteriormente, gracias al éxito de la Nouvelle Cuisine francesa a partir de 1960 (con chefs como Jean et Pierre Troisgros, Michel Guérard, Paul Bocuse, Alain Chapel o Alain Senderens), algunos cocineros alcanzaron el estatus de "autores" reconocidos.

Pero fue en España donde la cocina de vanguardia, con su auge sin precedente desde el año 1994 transformó profundamente el estatus del chef o cocinero. No se puede hablar de esta "edad de oro" sin referirse al ya citado Ferran Adrià, “cocinero artista”, que en 2007 fue invitado como cocinero y como artista en la Documenta de Kassel, una de las mayores citas mundiales del arte contemporáneo, «alquimista» (Le Monde 1) de los fogones y jefe de fila de una cocina rotundamente vanguardista. Gracias a esta consagración reciente de la cocina y de los cocineros, así como el nombramiento, en 2013 de "El Celler de Can Roca" como número uno entre los mejores restaurantes del mundo (año de la presentación del proyecto "El Somni” ante la prensa), ha sido posible un experimento tan creativo, y también arriesgado como "El Somni”. Algunas de las características principales de "El Somni" se basan claramente en los principios gastronómicos españoles de vanguardia. En 2006, un año antes de presentar su obra en la Documenta de Kassel (Alemania) con otros 130 artistas, Ferran Adrià enumeraba las principales bases de la cocina de vanguardia. El chef destacaba la ayuda de las nuevas tecnologías (en "El Somni" hay imágenes 3D, entornos y también robots musicales), la creciente codificación del lenguaje culinario gracias a colaboraciones con otras artes y medios de comunicación (en "El Somni” se unen música, videoarte, diseño, poesía y cocina y enología), así como la deconstrucción y flexibilidad de la estructura clásica de la comida en el menú degustación (en "El Somni" la comida basada en la ópera se compone de 12 pequeños platos que van con el progreso narrativo de la historia que se cuenta). Por último, "El Somni" es el resultado de un proceso de investigación que comenzó con la colaboración entre los hermanos Roca y Franc Aleu en dos proyectos anteriores: "Nauta”, un espectáculo tecnogastronómico (aperitivo y degustación de vinos en un esquema de 10 pantallas circulares realizado en 2006 en Barcelona), y el "Gol de Messi”, un postre servido en 2014 durante el tour por América del Sur de los hermanos Roca), cuyo reto era cambiar una idea (aquí, una fuerte emoción futbolística) en un plato.

\subsection{La cena gastronómica como espectáculo: actuaciones en la alta cocina española}

Además de la clara y declarada inspiración por parte de los hermanos Roca y de Fran Aleu, en el genéro operístico, uno podría notar la evidente filiación entre el espectáculo culinario ofrecido en El Somni y los banquetes de lujo tales como los que fueron organizados por Vatel en Francia en el siglo XVII. Por cierto, Joan Roca cita al francés Vatel como uno de los inspiradores de su proyecto: "Y con El Somni hemos querido llevar al máximo nivel este concepto de transversalidad haciendo nuestro homenaje pendiente, soñado hasta ahora off the record, a un admirado Vatel”. Según el investigador D. Michel, lo que se designaba con el término de "ambigú" era una cena-aperitivo, una especie de bufet sentado donde todo el escenario — desde la disposición de la comida hasta los elementos decorativos - se concebía como una obra de arte (Michel, 1999). En el castillo de Vaux-Le-Vicomte en 1661, Vatel organizó una fiesta para la visita del rey Luis XIV a Bouquet en la que los placeres de los ojos y el gusto agregaron algo a la música de 24 violines y vajilla de oro o plata dorada. Más tarde, 
en agosto de 1671, cuando Vatel trabajó como superintendente del Gran Conde en el castillo de Chantilly, organizó un extraordinario banquete en honor del rey Luis XIV con la magnífica alternancia de espectáculos en vivo (teatro, conciertos), actividades de ocio y comidas que duró varios días. También a propósito de los siglos XVIII y XIX, el historiador francés Jean-Paul Aron designó las cenas de lujo como “cenas-espectáculo”, en las que todo, desde el diseño de las mesas, la disposición de las luces y de los invitados y hasta la composición de los menús revelan una sofisticada dramaturgia (Aron, 1988).

En los últimos años, sólo dos artículos desarrollaron el tema de la dramaturgia propia de los banquetes o las cenas gastronómicas: uno centrado en la tendencia reciente de mostrar el trabajo del chef a los invitados, abrir el espacio de la cocina (Ferguson, 2005) y el otro en la noción de "escenario" para identificar la escena gastronómica como un acto altamente teatralizado y ritualizado en restaurantes de lujo brasileños (Gómez, 2008).

La concepción de la comida gastronómica como un espectáculo se ha extendido en los restaurantes más vanguardistas de España. ¿Significa eso que estamos presenciando una especie de "hyperstaging” de la cena gastronómica? En el restaurante de Ferran Adrià, los invitados entraban en la cocina para presenciar la actuación del personal. Los chefs Quique Dacosta (restaurante "Quique Dacosta”) o Andoni Luis Aduriz (restaurante "Mugaritz") han declarado que ofrecen un espectáculo diario. En el restaurante madrileño de cocina fusión "Diverxo", el espectáculo es ofrecido por los camareros que regularmente realizan el acabado de los platos delante de los clientes. El joven chef recientemente distinguido con tres estrellas Michelin, David Muñoz, visita brevemente el comedor para hacer su propia actuación como, por ejemplo, con el acabado del pulpito al estilo shabu-shabu. En "El Celler de Can Roca”, el espectáculo comienza con una visita a la bodega. Durante esta visita, los invitados pueden tocar seda antes de degustar un vino de Burdeos para reconocer esta particularidad en su densidad y después meter sus manos en un recipiente lleno de pequeñas bolitas metálicas antes de disfrutar las burbujas de un cava.

Nos enfrentamos a lo que parece ser una auténtica tendencia en los diversos restaurantes gastronómicos de España hacia la experiencia multisensorial y el espectáculo.

\subsection{Más allá del espectáculo: las relaciones entre “El Somni”, el teatro y la performance}

Cabe señalar que "El Somni” va más lejos del mero espectáculo culinario, entendiendo el espectáculo como un concepto muy amplio que remite a la "representación visual de todo tipo de manifestaciones" (Pavis, 2007: 14). La experiencia se podría identificar como a medio camino entre el género de la ópera, la performance artística y el teatro.

“El Somni” es una representación muy meticulosamente preparada, con una división del espacio inspirada en el género operístico en el que la escena, es decir, la mesa con los comensales, está rodeada por lo que podríamos ver como unos bastidores, de los que salen los camareros, para luego desaparecer por el mismo lugar por donde entraron.

Todos los protagonistas de "El Somni” son alternativamente actores y/o espectadores que habitan un dispositivo organizado con un tempo peculiar y estudiado, con una diégesis fija que relata una historia de amor y de muerte. Joan Roca define "El Somni” como “una ópera gastronómica” dirigida por Fran Aleu con un ideario e imaginario fantásticos con los que se eleva la cocina a categoría escénica o se 
incorpora a la ópera la experiencia gastronómica de comer y beber, experiencias sensoriales que hasta ahora habían quedado protocolariamente excluidas de ella.

Pero al ser también una cena "pop-up", elaborada en el lugar — con todos los riesgos que la cocina en vivo puede tener-, "El Somni” puede también ser considerada una performance, tal como la entiende Joseph Danan: “un acto en presente en el que el texto es secundario” (Danan, 2016: 8). En la performance, la acción puede situarse fuera del escenario (lugar concebido adrede para la representación convencional), de modo que el concepto de mimesis se cuestiona: "la acción es cumplida por la escena en sí, la escena no es forzosamente una imitación de la realidad” (Pavis, 2007: 14). Lo que importa más en una performance es el cumplimiento en el presente de un acto que no ha sido planeado ni escrito precisa y anteriormente a su concretización. Una performance es irrepetible, única, y constituye a menudo un medio de búsqueda para su creador. La cena dada en "El Somni" fue única, y dio lugar a unos platos y maridajes inéditos para la carta del restaurante "El Celler de Can Roca”. Como en una performance se da importancia al proceso de creación, al "work in progress”, y a la actuación de su público, que se convierte en co-autor de la obra, en la propuesta de los hermanos Roca, los espectadores tienen influencia en el desarrollo de la comida y del relato. El comensal de "el Somni” tiene pues un papel peculiar, ya que es a la vez público y actor (performer) en la obra gastronómica y contribuye a su construcción general, a su ritmo (según la velocidad a la que se degustan los platos y los vinos). En este caso el público, además, destruye la obra performativa al mismo tiempo que la está construyendo.

“El Somni” sigue así dos de las cinco tendencias del arte performativo según P. Pavis en el Diccionario del teatro. Se trata primero de realizar una manera de "ceremonia ritual y mítica” —y en esta acepción se le otorga dimensiones antropológicas y culturales al género de la performance, que va pues más allá del teatro, al incluir todo tipo de rituales: el juego, el deporte (Danan, 2016: 7) — y en nuestra perspectiva, la gastronomía. La segunda tendencia de la performance en la que "El Somni” se inscribe sería la del "body art”, o arte corporal, pues los cuerpos de los comensales-performers son utilizados para incorporar parte de la obra (los platos y los vinos), incluso a veces estos comensales son puestos en situaciones emocionalmente delicadas de rechazo o de recelo ante algunos platos, como veremos más abajo en este trabajo.

De modo que la cena de "El Somni” es una forma híbrida, que tiene que ver tanto con el registro de la gastronomía y del arte culinario como con el registro del espectáculo teatral y el de la performance. Por consiguiente, necesitamos herramientas de análisis artístico para comprender mejor las diferentes dimensiones de tal obra de arte.

\section{Metodología}

A partir de las investigaciones teóricas de los años 60-70 sobre el dispositivo, y sobre todo el pensamiento de Michel Foucault, un grupo de científicos franceses (Stéphane Lojkine, Philippe Ortel, Arnaud Rykner, Monique Martinez, Euriell Gobbe Mévellec, Emmanuelle Garnier) han cuestionado la noción en los campos de la literatura y del arte en general. Esta corriente fue acuñada por Bernard Vouilloux, en la revista Critique, bajo el nombre de "l’École de Toulouse" (lugar donde nació la crítica de la teoría de Foucault). Según los fundadores de este movimiento, la utilización del concepto de dispositivo puede ayudarnos a renovar el acercamiento a las producciones artísticas y literarias, en la medida en que ofrece la posibilidad de cruzar las artes de lo escrito, las artes de la imagen, la comunicación y la sociología. Un dispositivo se puede definir como una red de elementos heterogéneos 
organizados para producir, en un espacio dado, unos efectos de sentido en el receptor. Lo constituyen tres niveles articulados y superpuestos:

el nivel geométrico o técnico (la organización de los elementos ubicados en el espacio en la ficción)

el nivel pragmático o escópico (la interacción de varios actantes bajo la mirada de un tercero) el nivel simbólico (valores semánticos y axiológicos asociados con la organización espacial).

Según P. Ortel:

"Cuando un dispositivo parte de un arreglo técnico o de cualquier realidad dotada de la misma función que regula las relaciones entre sujetos, entran en juego otras dos dimensiones: una dimensión pragmática, evidente en el caso de las herramientas de comunicación, ya que median nuestros intercambios, y una dimensión simbólica, en el sentido actual de “valores”, pues un dispositivo no tendría significado ni legitimidad sin los valores semánticos y axiológicos que lo impregnan”(Ortel, 2011: 207).

El dispositivo se alimenta con disciplinas muchas veces compartimentadas, incluso en el siglo de la interdisciplinariedad, y ofrece un espacio común de análisis que le confiere toda su legitimidad. El concepto marca también de manera definitiva el arte con el sello de la variabilidad, en la medida en que se construye la significación del objeto artístico en la intersección entre los signos y su percepción. Como lo enuncia Philippe Ortel, quien define el "entre deux" como uno de los parámetros claves del funcionamiento de estas representaciones, un dispositivo es una "matriz de interacciones potenciales, o más aun, una matriz interaccional" (Ortel, 2008: 33).

Debido a la complejidad de su alcance, a la heterogeneidad de su género - arte culinario, teatro, performance-, y dado que, como veremos más adelante, el contexto del experimento es tan significativo como el experimento en sí, la propuesta de los Roca merece ser estudiada con una perspectiva amplia y multidimensional. Las herramientas aportadas por la crítica de los dispositivos son suficientemente flexibles para analizar "El Somni” en sus aspectos culinarios, pero también como una performance y como un objeto sociológico, con el fin de poder determinar sus características innovadoras y transgresoras.

\section{Análisis y resultados}

\subsection{El nivel técnico (I)}

El dispositivo técnico de "El Somni” comprende el conjunto de los elementos materiales que componen el experimento. La inscripción de la performance gastronómica en un lugar inusual, el centro de arte Arts Santa Mònica en Barcelona, espacio dedicado habitualmente a exhibiciones, instalaciones o performances de artes plásticas, los equipamientos audiovisuales necesarios a la difusión de las imágenes, la música y los sonidos, así como las herramientas necesarias a la prestación gastronómica (mesa, sillas, vajilla).

La noción de espacio-tiempo es el nivel más necesario y fundamental en el dispositivo. La organización dentro de un espacio tiempo de los elementos es fundamental en el dispositivo ya que sin esta organización no puede surgir la interacción con el usuario ni tampoco el significado simbólico que propone el dispositivo. 
En el caso de nuestro objeto de estudio, el lugar elegido para "El Somni” fue el Centro de Artes Santa Mónica de Barcelona donde se configuró un espacio que se dividió en dos partes ubicadas en plantas diferentes: una no visible, la cocina - a diferencia de la tendencia habitual de mostrar la cocina como espectáculo- - yna visible para los participantes del experimento: una mesa redonda con 12 asientos.

La zona visible está dotada además con maquinaria de alta tecnología compuesta por 5 pantallas anchas (4 en círculo detrás de los invitados y una insertada en el centro de la mesa), los robots musicales de Roland Olbeter reproduciendo la música en vivo de un verdadero cuarteto de cuerdas y numerosas cámaras, proyectores de vídeo y puntos de luz que penden del techo.

La zona no visible, la cocina, solo es accesible al personal y está claramente aislada de las escenas visibles. En "El Somni", la cocina se utiliza como un laboratorio secreto cerrado, no como un escenario teatral abierto a la vista de los clientes. Durante el experimento, los chefs permanecen ocultos para los invitados, preparando los doce platos diferentes en su cocina remota. Esto revela la forma en que los Roca conciben su contribución al experimento: se niegan a interrumpir el espectáculo y así romper la ilusión que crea. De la misma manera que los cocineros no están en el escenario principal de la actuación, el papel de los camareros también es muy limitado en este mismo escenario: traen silenciosamente los platos a los invitados. Aquí, sin el acabado de los platos delante de los invitados, el personal es casi invisible. Todo parece estar hecho para que los invitados se centren en el espectáculo que ocurre en la mesa y detrás de ellos, y dejarlos solos con la disposición.

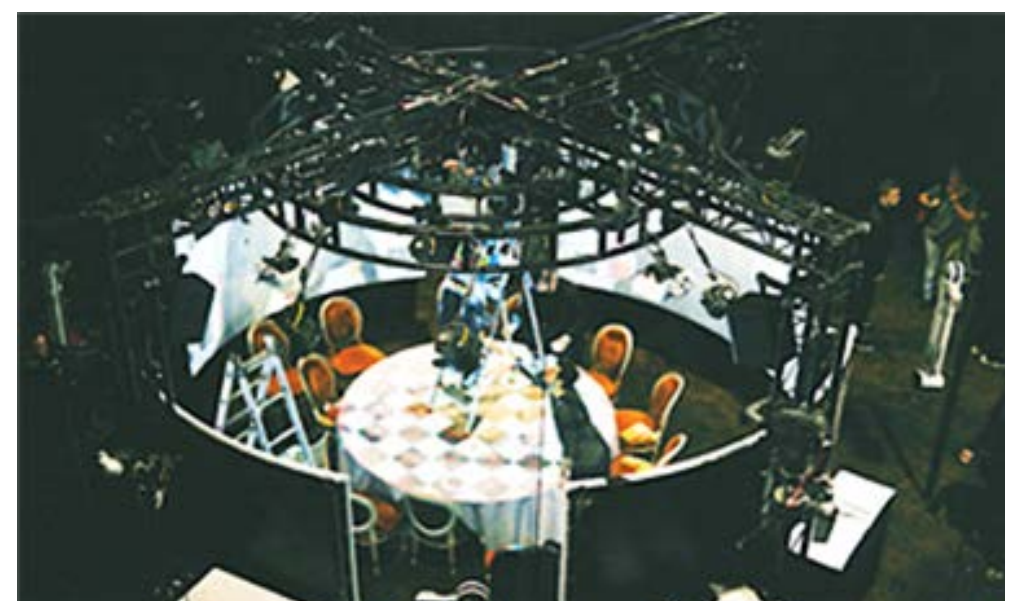

Fig. 1. Disposición técnica de "El Somni"

Asimismo, no olvidemos tampoco que los comensales del experimento están siendo filmados en continuo por distintas cámaras fijadas en el techo y en los laterales. Erving Goffman observó que las actividades sociales cotidianas y las interacciones eran en realidad actuaciones en las que cada individuo desempeñaba un papel socialmente predefinido, en un marco, o "fachada" que el individuo mismo fija y establece (Goffman, 1973: 29). El mero acto de compartir una comida alrededor de una mesa ya es una actuación social en la que cada invitado está interpretando una parte de la composición. Así que al filmar esta actuación y sus actores con el fin de crear una película, se está duplicando esta dimensión de actuación, esta "presentación de sí mismo" que resulta ya agudizada por la situación inducida por la comida, acontecimiento social por antonomasia. Cuando se filma, los invitados están desempeñando un papel dentro de sus papeles de comensales, como en una "mise en abyme”. El hecho 
de que todo el experimento sea filmado (I) influirá fuertemente en los actores (los invitados) y en sus interacciones (II).

\subsection{El nivel pragmático (II)}

Cualquier dispositivo tiene una dimensión pragmática (la pragmática estudia el lenguaje en situaciones concretas de enunciación) vinculada con la dimensión técnica, ya que es una matriz propicia para las relaciones entre los sujetos, los intercambios entre los diferentes actores, sean esos internos o externos, espectadores internos y convidados del experimento u observadores y actantes externos como lo son los camareros y los creadores observadores.

La mesa es un microcosmos teatralizado que sintetiza gracias a su diseño y su gramática las convenciones y reglas sociales de la sociedad en un período dado, como por ejemplo lo fue el servicio “a la francesa” utilizado en toda la Europa aristócrata en los siglos XVII-XVIII, que estriba en una organización precisa que refleja los estamentos sociales. La atribución de las plazas en la mesa marca una diferenciación social, puesto que "las posiciones centrales dan a quien las posee un mayor número de posibilidades de obtener los platos que desee consumir” (Poulain y Neirink, 2007: 58). Al contrario, en "El Somni", la circularidad perfecta de la mesa —elemento técnico central que determina las relaciones pragmáticas en el experimento-, así como la simultaneidad precisa del servicio de platos (un servicio dicho "americano" en que se sirven los manjares ya puestos en platos individuales, a cada convidado) parecen establecer una estricta igualdad entre los invitados. ¿Quiénes son los 12 invitados? Ferran Adrià, famoso cocinero español; Rafael Argullol, poeta y novelista; Miquel Barceló, artista plástico; Joël Candau, antropóloga francesa; Bonaventura Clotet, médico experto en virología; Nandita Das, actriz y directora india; Abderrahmane Kheddar, ingeniero argelino; Ben Lehner, biólogo británico; Harold McGee, científico y escritor estadounidense especialista en gastronomía; Freida Pinto, actriz y modelo india; Josep Pons, conductor; y Lisa Randall, física teórica estadounidense. Cada uno es un especialista reconocido en su propia área y todos los campos tocan uno de los géneros artísticos o medios que aparecen en "El Somni". La reunión de expertos de diversos campos para que la recepción y la comprensión del experimento vaya más allá del mero ámbito gastronómico revela cuán ambicioso es el anhelo de Fran Aleu y de los hermanos Roca: no sólo «arte total» sino también "ciencia total”.

Además, la cena propuesta alude claramente a otra cena fundadora en la cultura cristiana: la Última Cena que Cristo comparte con sus apóstoles. El número doce se repite varias veces: los invitados son doce, como los apóstoles. ¿Serían los invitados los testigos de un momento único, a la vez simbólica (el cumplimiento de la unión de numerosas formas artísticas con la alta cocina) y dramáticamente (esta unión es un desafío tan grande que sin duda será el primero y el último de esta índole)? Pero, ¿dónde está Cristo? No hay trigésimo convidado en “El Somni”. De modo que si de eucaristía se trata, ¿de quién se están “comiendo el cuerpo”?

La eucaristía, que se puede considerar como una forma de antropofagia simbólica, encuentra un eco en un episodio de la cena que se comentará más abajo. Después de la muerte violenta de Adonis, joven y hermoso héroe, cuya imagen se proyecta en las pantallas del dispositivo, llega un plato de carne poco hecha, de colores rojizos: Pichón y remolacha, una metáfora perturbadora y comestible del cuerpo sangriento de Adonis. 


\subsection{El papel de las pantallas}

El papel central y la posición de los invitados no deben hacernos olvidar el gran papel del nivel material del dispositivo. "El Somni" parece ser un peculiar dispositivo artístico en el que los elementos técnicos son no sólo visibles y extremadamente significativos, sino también son omnipresentes.

Las pantallas están por todas partes en "El Somni": rodean a los invitados para que no puedan mirar hacia arriba sin encontrar una pantalla, y si quieren mirar hacia abajo, se encuentran con otra pantalla incrustada en la mesa. Si nos referimos a la etimología de la palabra «pantalla», designa originalmente un tabique vertical fijo o móvil que se utiliza para dividir una habitación y así proteger de las corrientes de aire, calor o luz, o para proporcionar ocultamiento o privacidad. Así que la pantalla es en origen un objeto cuyo propósito es separar, ser un obstáculo para la vista. El hecho de encontrarse con un obstáculo para la vista desencadena el deseo de cruzarlo para ver más lejos o ver a través de dicha pantalla. La opacidad de la pantalla hace que el impulso escópico del invitado (el deseo de mirar) crezca. En "El Somni", las pantallas están marcando un extraño espacio de representación, ya que está hecho de los medios cuerpos (bustos y cabezas) de los doce invitados sentados a la mesa. El diseño de las pantallas está cortando los cuerpos de los invitados, así que no hay acceso a los cuerpos enteros, de manera que se puede interpretar que esta demarcación hace desaparecer la dimensión biológica de la comida en beneficio de una idea más intelectualizada de comer.

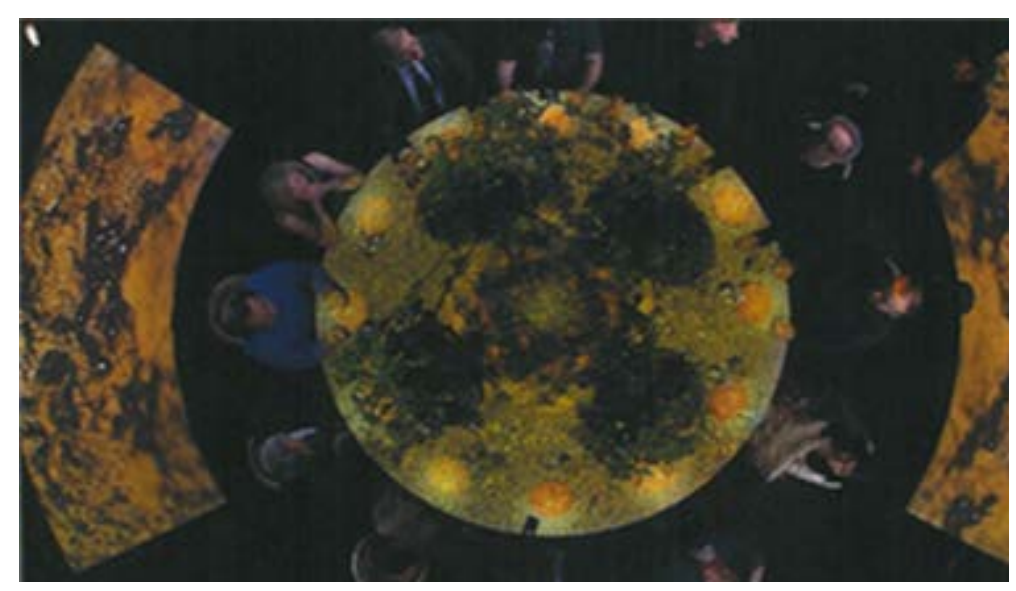

Figura 2. El espacio de la representación

En "El Somni", las imágenes y sonidos creados por Aleu componen un poema visual ilustrado también por la música, los platos y los vinos. Cada imagen está fuertemente vinculada con los otros elementos de la interpretación. De alguna manera, las imágenes que se mueven alrededor de los invitados están prefigurando explícitamente el plato servido después. Por ejemplo, cuando los personajes de la historia entran en el jardín de las Hespérides, se proyectan imágenes abstractas caleidoscópicas sobre una música de oración budista conformando así una agregación multicolor y sobrecargada de patrones. Algunos patrones visuales son inquietantes, otros son sorprendentes, la mayoría de ellos evocan la vida silvestre natural con una estética india. El plato servido es un plato principal, el «mandala» (la palabra designa en sánscrito un círculo budista simbólico), una hermosa placa multicolor compuesta por dos elementos principales: cordero asado y flores de alcachofa, así como muchos elementos pequeños como sorbetes, salsas, varias espumas con ácido, picante y sabor cítrico. Las imágenes y sonidos están interviniendo entre el plato de mandala y el impulso escópico, es decir, el deseo de ver, de los invitados. Por lo tanto, las pantallas tienen un doble papel: son el marco prominente para el experimento y el soporte para las imágenes proyectadas: muestran y ocultan al mismo tiempo. 


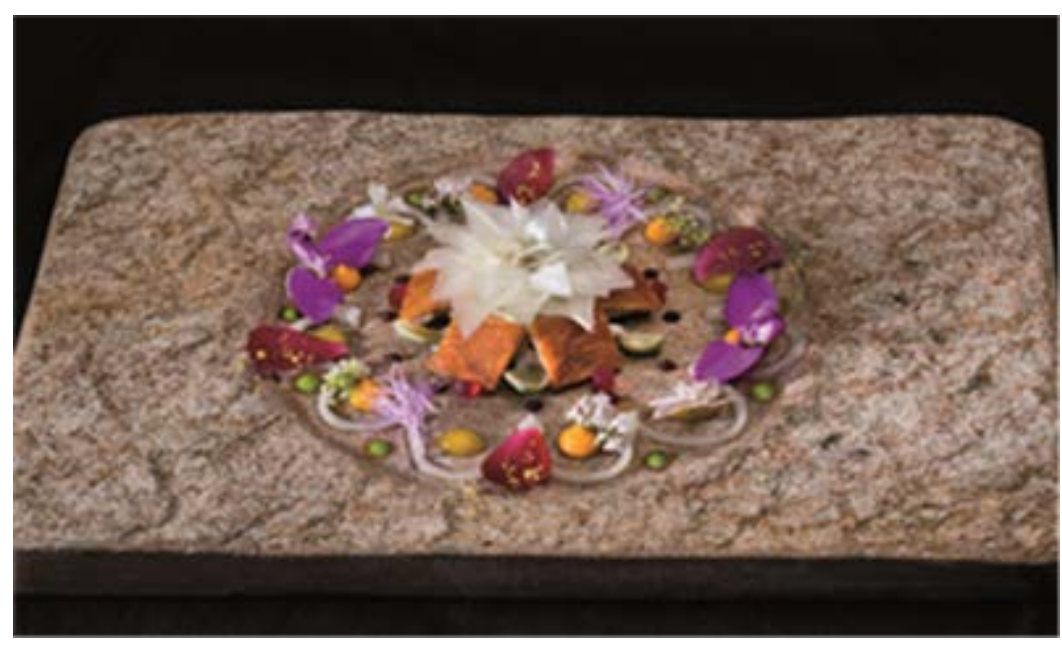

Fig. 3. El plato de «mandala»

La prominencia de la pantalla, de lo técnico del dispositivo, altera las dimensiones sociales de la comida. Ya notamos que todo el dispositivo de "El Somni" parece estar hecho para quitar a los cocineros y a los camareros del escenario y dejar al invitado solo en el ambiente creado. ¿Está el experimento alcanzando el punto extremo de la lógica de la degustación como una actividad totalmente individual e incluso solitaria? Antes del comienzo de la cena, Joan Roca pide a los invitados que aprovechen al máximo los silencios y eviten conversar. "El Somni" no es una comida normal, es una comida en la que las interacciones verbales entre invitados no son bienvenidas, exactamente como sucede cuando vamos al teatro convencional o al cine. Las luces producidas por las pantallas, su tamaño, su disposición circular, así como la calidad de definición de las imágenes en 3D tienen propiedades hipnóticas en los invitados. De hecho, la omnipresencia, la variedad y la complejidad de los estímulos producidos por las pantallas perturban el curso de la comunicación tradicional. Ver los diferentes episodios de la odisea de Astrid (el personaje principal) requiere toda la atención del invitado y, además, hablar en esos momentos de acción se hace difícil. ¿Es más fácil hablar en los momentos de degustación? En un nivel pragmático, más allá de la rudeza de hablar con la boca llena, la degustación también puede considerarse como una especie de «anti comida». Cuando C. Champion (2010) cita las historias de degustación recogidas durante 2007 en la Documenta de Kassel por R. Hamilton y Vincente Todoli destaca una aparente incompatibilidad entre la dimensión colectiva de la comida y la práctica de la degustación. A propósito de esta pantalla gigante, casi invasoras, se podría hablar de una disonancia interna del dispositivo (Ortel), que quizá comunica una pregunta acerca del desfase entre realidad y fantasía, entre carnalidad y sueño. Cuando la realidad aumentada, ficticia, se superpone a la experiencia, hasta incluso ejercer una dominación sobre la experiencia real: ¿Qué ocurre con las sensaciones físicas? ¿Son aumentadas o, al contrario, se apagan?

Pero lo más sorprende, a pesar del consejo del chef y de todos los obstáculos para la comunicación entre los invitados, es que a lo largo de todo el experimento los invitados han generado «un susurro colectivo como en la Torre de Babel, en la que el catalán, el español, el inglés, los idiomas franceses se estaban derritiendo en una banda sonora única». El diálogo verbal no desapareció.

Los hermanos Roca pensaron que el espectáculo enmudecería a los espectadores, pero no fue así, de modo que incluso en medio de tantas estimulaciones diversas, parece imposible aislar la experiencia 
gastronómica de lo que constituye la comensalidad pues se establecen vínculos e intercambios entre los comensales (Fischler, 2012), tanto en los niveles pragmático (II) como simbólico (III).

\subsection{La dimensión simbólica/axiológica: un menú transgresor}

Si seguimos la sucesión de la fábula contada a lo largo del experimento, primero viene el aperitivo: «Bonsái de sauce llorón», que presenta en su base diversos aperitivos vanguardistas. Luego, los entrantes: "Caldo vegetal" anunciando la apertura del banquete y como un bebedizo mágico, el comienzo del sueño; "La luna”, trufa negra y blanca con mousse de anchoa; "Serpentarium” anguilas con especias; y "Bajo el mar", siete variedades de mariscos preparados de siete maneras diferentes. Después, tres platos principales: "Mandala"; "Cordero con alcachofas"; "Pecho de la paloma" elaborado con rosas, fresas y gotas de rocío; y «Ganso à la royale», hecho con el ganso, hígado, sangre y zumo de remolacha. Además de dos postres: "Helado de levadura” con puré de cacao, lichi deshidratado y merengue y “Nube de azúcar de algodón”, que es una nube de azúcar, hilo de azúcar, flores, caramelos y miel.

En este progreso general y clásico de la comida, algunos otros platos vienen como sorpresas, insertando pausas juguetonas o brechas desconcertantes. Por ejemplo, «La manzana» —manzana caliente hecha con caramelo soplado y llena de manzana asada - es un trampantojo que engañosamente anuncia el postre y rompe así las expectativas del invitado.

El plato más transgresor es el llamado «Piedad/muerte», que se sirve en la décima secuencia de "El Somni” porque en él se aborda uno de los grandes temas del Arte y la Literatura, que es la muerte. El plato llega justo antes de los dos postres - momento dulce- y se corresponde con el momento de la muerte de Adonis y su entierro, así como la descomposición proyectada en imágenes a través de las pantallas. Como no se puede clasificar en ninguna de las fases conocidas de la comida gastronómica, este plato está realmente rompiendo con el progreso lineal y narrativo de un menú al uso. Aquí está la descripción de la escena tal como aparece en el libro "El Somni":

“Adonis muere, no pudo sobrevivir a su propio ataque. Su cuerpo está inmóvil sobre el mármol. Las campanas sonarán. El aire está lleno de la fragancia de la compasión, del olor a incienso, y las flores se secan. Adonis está rodeada de velas y Astrid mira al cadáver con compasión” (Aleu, El Celler, 2014: 135).

Esta es la descripción del plato que se sirve siguiendo una idea clave, la piedad y la muerte. El plato con el que se hace saborear esta idea es un «Parmentier de patatas violeta con médula y caviar, humo de incienso y flores malva», que se acompaña con Barbadillo, Botella Reliquia Oloroso de 150 años (DO Manzanilla - Sanlúcar de Barrameda). El plato se sirve en mármol y el vino en copas Nachtmann con la música del compositor Bernat Vivancos interpretada por el Coro de la Radio de Letonia y cuarteto de violonchelo: Pau Codina (solista), Marta Requena, María Bou, Alba Aro y Oleguer Aymamí con Voz y violonchelo y un vídeo de Aleu.

Cuando el plato llega, el invitado primero ve una campana llena de humo. A su alrededor, escucha música de violonchelo y un coro femenino y ve imágenes de velas en la oscuridad: el cadáver de Adonis tumbado sobre una superficie gris, Astrid como una Piedad llorando la muerte de su amante y finalmente imágenes en 3D de todo tipo de lombrices. En este mismo momento se abre la campana y el humo perfumado se disipa lentamente para revelar un pequeño tazón de mármol gris que contiene una sopa rosada: helado de genciana esferificado médula, ruibarbo con caviar, trompetas de muerte, 
humo de incienso y artemisa para evocar el olor de la piedra fría. Este plato evoca una pequeña tumba abierta: es la idea de la muerte y entierro convertido en un plato.

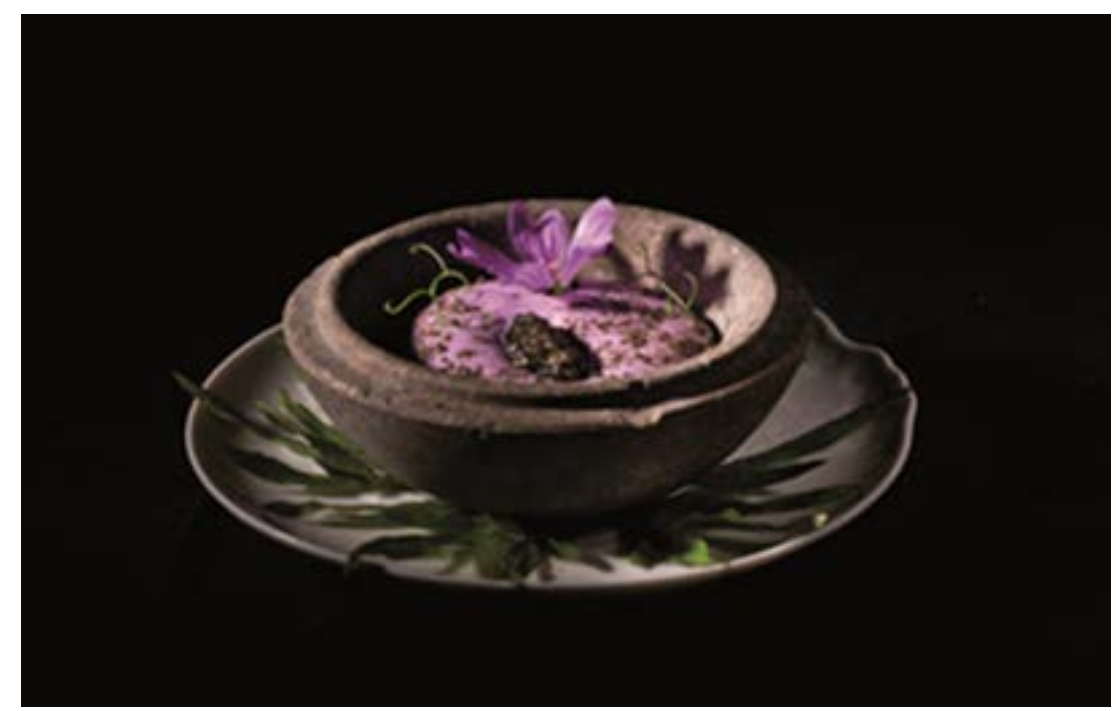

Fig. 4: El plato "Piedad/Muerte”

Todos los niveles del dispositivo — técnico, pragmático y simbólico- convergen repentinamente como cristalizados para tener sentido. La narratividad, discursividad, el tiempo y el espacio son derrotados y se instala otra lógica: la lógica escénica (Rykner, 2001). Esta escena marca el éxito del experimento, ya que en este momento todos los sentidos del receptor — gusto, oído, tacto, vista, olorconvergen para crear una intensa emoción que los comensales recordarán (no sólo mentalmente, también en sus cuerpos) durante mucho tiempo después del final del espectáculo.

Además, la décima secuencia tiene una dimensión fuertemente transgresora, ya que sacude los estándares de la experiencia gastronómica abocados a la felicidad, dando lugar a disonancias y despertando primitivos «miedos» en las mentes de los receptores. Cuando llega el momento de probar el plato de «Piedad/Muerte», comer no es lo primero que el invitado siente hacer en ese momento. En realidad, algunos comensales pueden experimentar disgusto, tristeza, miedo, desolación y otras emociones similares, ya que han sido sumergidos en un ambiente frío de muerte, polvo y descomposición. Sin embargo, el invitado está situado detrás de esta hermosa pequeña tumba abierta, en la que reconoce, como un señuelo, un producto de lujo, el caviar que despierta el deseo de degustación, con lo que el fuerte impulso vital choca violentamente con la muerte evocada por el plato y por todas las señales a su alrededor. De hecho, esta escena aborda una considerable oposición simbólica: los principios de la vida frente a los de la muerte.

Aquí es donde el dispositivo se invierte, volviendo a la dimensión biológica fundamental de la comida: los seres vivos comen para vivir. De esta forma el círculo se completa porque el experimento más intelectualizado y sofisticado finalmente nos devuelve a los fundamentos, al origen más profundo de nuestras prácticas alimentarias.

Como la tecnología produce las condiciones para un diseño eficiente (nivel I, técnico), la emoción del invitado causada por la cristalización de sus cinco sentidos (nivel II, pragmático) permite el despliegue de valores antagónicos (nivel III, simbólico). En ese momento llegamos al clímax de este experimento de "cocina tecnoemocional” o "cocina de vanguardia”. 


\section{Discusión y conclusiones}

Gracias a la teoría de los dispositivos, hemos profundizado en el alto nivel de imbricación de los niveles técnicos (I), pragmáticos (II) y simbólicos (III) de la ópera gastronómica "El Somni”. Llegamos pues a las siguientes conclusiones:

1. El componente técnico/tecnológico omnipresente y la ineludible comensalidad. Las pantallas que rodean al comensal limitan el estrecho espacio de la representación, pero también se colocan entre el plato y los invitados con el objetivo de aislarlos en el experimento y modificar las interacciones entre ellos. Sin embargo, los comensales sentados alrededor de la mesa continúan portándose como seres sociales dispuestos a interactuar con los demás, hablando, aunque fuera en susurros. De esta forma, se demuestra la imposibilidad de aislar la experiencia gastronómica de la comensalidad.

2. La intencionalidad artística. Pese a que "El Somni" esté inscrito en la larga tradición de la cena ligada con el espectáculo, esta intencionalidad del siglo XXI de crear la obra de arte total es innovadora. Para los Roca, el espectáculo "El Somni" es a la vez un experimento de investigación y desarrollo, y también la realización de su sueño prometedor y artístico de concentrar en una cena única toda la paleta de fenómenos ligados a los sentidos gastronómicos. De hecho, "El Somni" es mucho más que una fantasía elitista y efímera. Este laboratorio creativo genera prototipos gastronómicos inéditos, elabora nuevas formas de comunicación en torno al tema de la cocina y construye un modelo inspirador de colaboración interdisciplinaria.

3. La transgresión. La aplicación de la crítica de los dispositivos a este experimento gastronómico confirma que algunas piezas (platos+imágenes + música+aromas+escenografía) no sólo crean emociones positivas, sino que también dan lugar a disonancias, suscitan temores primitivos o provocan considerables oposiciones culturales. En la décima secuencia de "El Somni”, cuando el personaje de Adonis muere, todos los medios y géneros artísticos involucrados en el experimento -imágenes, sonidos, música, diseño y cocina- convergen para contradecir las expectativas de los invitados y provocar un sentimiento unánime y desagradable. El episodio "Piedad /Muerte” es, pues, una escena transgresora que despierta impulsos biológicos y físicos en medio de una de las comidas más sofisticadas jamás hechas. Y aquí es, sin embargo, donde la teoría de dispositivos muestra cómo se vuelve a la dimensión biológica fundamental de la comida: los seres vivos comen para vivir. Los comensales son seducidos por el plato que degustan, pese a las emociones contrapuestas que sienten.

De manera que el círculo se completa: el experimento gastronómico-artístico más intelectualizado y sofisticado finalmente nos devuelve a los fundamentos del ser humano y al origen más profundo de nuestras prácticas alimentarias.

*Investigación financiada. Este artículo es producto del proyecto de investigación francoespañol titulado “Aplicación de la metodología francesa de dispositivos a los restaurantes de cocina de vanguardia experimentales” financiado por ISTHIA (Instituto Superior de Turismo, Hotelería y Alimentación) y apoyado por el laboratorio LLA-CREATIS Letras, Lenguajes y Artes) de la Universidad de Toulouse - Jean Jaurès, en el marco de un eje de su programa de investigación 2015-2020, Intermedialidades. 


\section{Referencias bibliográficas}

Aleu, F. (2014): El celler de Can Roca. El Somni. Madrid: Lunwerg.

Aron, J.P. (1988): El espectáculo de la cena en el siglo XIX. En R. Stern (Ed.), À manger des yeux, l'esthétique de la nourriture (Comer con los ojos, la estética de los alimentos) (pp. 57-64). Bourdy:

Ediciones de Braconnière.

Champion, C. (2010): Hors d'œuvre, Essai sur les relations entre arts et cuisin. (Aperitivos, Ensayo sobre la relación entre el arte y la cocina). París: Gallardon: Menu Fretin.

Danan, J. (2016): Entre théâtre et performance, la question du texte, Arles: Actes Sud-Papier.

Ferguson, P. (2005): La ostentación culinaria. Nacimiento de un campo gastronómico. En J. Dubois, P. Durand \& Y. Winkin (Eds.). Le symbolique et le social. (La simbólica y el social). La réception internationale de la pensée de Pierre Bourdieu (La recepción internacional del pensamiento de Pierre Bourdieu) (pp. 92-102). Liège: Ediciones de la Universidad de Lieja.

Fink, B. (1995): Les liaisons savoureuses. Réflexions et pratiques culinaires au XVIIIe siècle, Publications de l'université de Saint Etienne, coll. "Lire le XVIIIe siècle”.

Fischler, C. (2012): “Comensalidad". En J. P. Poulain (Ed.), Dictionnaire des cultures alimentaires (Diccionario de las culturas alimentarias) (pp. 271-286). Paris: Prensas Universitarias de Francia.

Flandrin J. L. (1992): Chroniques de platine, Pour une gastronomie historique, Paris, Odile Jacob, coll. "Histoire".

Foucault, M. (1993): Surveiller et punir, la naissance de la prison (2d ed.). Paris: Gallimard.

Goffman, E. (1973): La mise en scène de la vie quotidienne. Les relations en public. Paris: Minuit.

Gomes da Costa, P. C. (2008): “Escenarios de la geografía: La espacialidad de las imágenes y sus significados”. En Z. Rosendhal \& R-L. Corrêa (Eds.), Espaçao e cultura, pluralidade de tematica (El espacio y la cultura, la pluralidad de temática), p. 187-209. Rio de Janeiro: UERJ.

Hartung, E. (2002): El arte del comer, de la naturaleza muerta a Ferran Adrià. Salamanca: A fuego lento.

Marcilhac, V. (2012): "Spaces and practices in the great restaurants of France”. In V. Marcilhac, V. Moriniaux (Eds.): Les établissements de restauration dans le monde (Establecimientos de restauración en el mundo) (pp. 59-92). Paris: L’Harmattan.

Medina, F. X. (2005): Food cultures in Spain (Culturas alimentarias en España.) Londres: Greenwood.

Michel, D. (1999): Vatel et la naissance de la gastronomie, Recettes du grand siècle adaptées par Patrice Rambourg. (Vatel y el nacimiento de la gastronomía, recetas del siglo diecisiete adaptadas por Patrice Rambourg) Paris: Fayard. 
Ortel, Ph. (2008): "Vers une poétique des dispositifs”. En Ph. Ortel (Ed.), Discours, image, dispositif (Discurso, imagen, dispositivo) (pp. 33-58). Paris: L’Harmattan.

Ortel, Ph. (2011): “El efecto del dispositivo en la narrativa cinematográfica” en F. Albera \& M. Tortajada, Ciné-dispositifs (Dispositivos del cine) (pp. 205-225). Paris: L’Âge d'homme. (La Edad Humana.) (Versión inédita en inglés: traducción de Franck Le Gac).

Pavis, P. (2007): La mise en scène contemporaine, Origines, tendances, perspectives. Paris: Armand Colin.

Poulain, J. P. \& Neirinck, E. (2007): Historia de la cocina y de los cocineros. Sant Boi de Llobregat: Zendrera.

Rancière, J. (2004): Malaise dans l'esthétique Paris: Galilée.

Rykner, A. (2001): “La scène sans la scène”. En M. T. Mathet, La scène, littérature et arts visuels (Escena, literatura y artes visuales) (pp. 196-211). Paris: L’Harmattan.

Saumell i Olivella, E. (2011): De la cuina al escenari: el teatre gastronomic en la posmodernitat. Universidad de Barcelona.

\section{Cómo citar este artículo / Referencia normalizada}

A C Yemsi-Paillissé, Y Acosta Meneses, M Martínez, E Calvo Gutiérrez (2018): “Aplicación de la crítica de los dispositivos a la cena performativa "El Somni” de El Celler de Can Roca y Fran Aleu”. Revista Latina de Comunicación Social, 73, pp. 1267 a 1283.

http://www.revistalatinacs.org/073paper/1306/65es.html

DOI: $10.4185 /$ RLCS-2018-1306

- En el interior de un texto:

...A C Yemsi-Paillissé, Y Acosta Meneses, M Martínez, E Calvo Gutiérrez

(2018: 1267 a 1283) ...

0

...A C Yemsi-Paillissé et al, 2018 (1267 a 1283) ...

Artículo recibido el 30 de mayo de 2018. Aceptado el 2 de julio. Publicado el 7 de julio de 2018 